\title{
Comments on BASA
}

\section{The Scientific Analysis of Social Action by Steven C. Hayes \\ University of Nevada - Reno}

Our goal in the behavior analysis of social action is not simply to promote social justice, but to examine the contribution science can make to that task. The combination of science and social action is a difficult one, primarily for the following reason: Social action must start with a goal. This simple fact can create two kinds of problems for the scientific analysis of social action: we can attempt to justify our goals and values with science and thereby distort the science. Or we can attempt to substitute scientific analysis for values and thereby distort the purpose of values.

All goals are ultimately beyond the reach of science. Science can tell us what may happen if a given goal is embraced. It cannot say whether the goal itself and its consequences are desireable, except by reference to still other values and other consequences. One has only to take a goal and say "so what?" to it to discover this. As back-up reasons are challenged again with "so what?" one of two things will happen: silence will fall over the conversation or the speaker will attempt to bully the listener with an appeal to values that are so universally held that they seem to stand as revealed truths (e.g., "and then we will all die!" to which the proper answer is "so what?")

In Skinnerian terms we can say it this way: the product of good science is tacts. Goals and values are both issues of reinforcement control, and their expression are as mands. The scientific analysis of mands allows us to tact the sources of mands, but such tacts cannot substitute for the social functions of mands. I say "do not do this or else!" You reply "the reason you say this is because of current aversive stimulation of such and such a variety." I say, "Yes, that is correct. And I repeat. Do not do this or else." Tacts are not mands, and do not serve the same functions as mands. Thus, we cannot have science do the actual work of values without distorting both.

For some, this makes social action subtly incompatible with science. But this situation is really no different than a clinician trying to help a client, or a scientist trying to test a theory. These goals, too, cannot ultimately be shown by science to be "correct."

Thus, social action is only in part subject to scientific analysis. The purpose of a scientific journal of this kind is not to justify goals and values, but a) to analyze them and b) to analyze means of their achievement. To encourage the analysis of goals and values is to encourage scientists to state them, to analyze their sources and consequences, and to note how these consequences themselves impact on still other goals and values. Such an analysis cannot justify values, rather it clarifies them. To examine their means of achievement requires that we state them, state what behaviors may promote or interfere with them, examine sources of control over these behaviors, and examine the consequences of changes in these behaviors.

Note that both forms of analysis start with clarity about what the purposes of the analysis are. Such clarity is essential for behavior analysis if it is to retain its contextualistic qualities (Hayes, Hayes, \& Reese, 1988; Hayes \& Haas, 1989). Behavioral analyses of social action can make a general contribution not only to social justice but also to the science of behavior analysis by pioneering a sensitivity to the goals of a behavioral analysis.

\section{The Role of Behavior Analysis by Roger Ulrich Western Michigan University}

Behavior analysis attempts to separate the universe of Human Actions into component parts via an examination of the elements and the relations of Life's Behavioral Complex. The Social and Cultural actions of the Human Species have wasted Mother Earth's resources more than any other existing life form.

The new journal Behavior and Social Issues must become more a part of the solution than the problem or else it, too, will deservedly become extinct. It must report truths that help all people become aware of the Earth's limits to growth and guide them as they learn to live with fewer resources.

If it fails to serve that ethic, it will receive neither the physical nor spiritual energy that is daily becoming more depleted as all life forms struggle to survive on a planet that daily becomes increasingly polluted. Unfortunately, this soiling of the Earth nest is perpetuated most by we so-called educated folks who write and read. No doubt, the new journal will be printed in English and read mainly by a very small group within the $5 \%$ of the World's population that each year exploits $40 \%$ of the total annual earth's resources used.

In whatever jargon with which we choose to communicate, we, as writers and readers, must come to grips with our own addiction to over-consuming and our own penchant to respond to short term reinforcers to the detriment of the long term continuity of Life itself.

Above all, may we sincerely strive to serve one another as each and every one of us comes to grips with the pain experienced from withdrawal and the realization that we are on the earth together with 40,000 others who die each day from starvation, not unrelated to our own abundance. 